\title{
Avaliação nutricional do farelo de algodão de alta energia no desempenho produtivo e características de carcaças de frangos de corte
}

\author{
Nutritional evaluation of cottonseed meal in high energy performance and carcass \\ characteristics of broilers
}

\author{
Cleidida Barros de Carvalho ${ }^{I^{*}}$ Wilson Moreira Dutra Junior ${ }^{\mathrm{I}}$ Carlos Bôa-Viagem Rebello ${ }^{\mathrm{I}}$ \\ Stélio Bezerra Pinheiro de Lima ${ }^{\mathrm{I}}$ Fátima Naomi Takata ${ }^{\mathrm{I}}$ Guilherme Rodrigues do Nascimento ${ }^{\mathrm{I}}$
}

\section{RESUMO}

O trabalho teve como objetivos determinar a composição química e energética do farelo de algodão produzido pela BUNGE Alimentos S/A, marca registrada como Farelo de algodão de alta energia $\left(F A A E^{\circledR}\right)$ e avaliar a inclusão deste no desempenho de frangos de corte. Determinou-se a composição química, aminoacídica e energética (utilizandose o método de coleta total de excretas, com duas coletas ao dia). Foi utilizado óxido férrico para marcar o início e o final da coleta. O nível de inclusão do alimento de teste na ração referência foi de 20\%. O desempenho foi avaliado com a inclusão do farelo de algodão no período de nove a 42 dias. Durante os primeiros nove dias, os pintinhos receberam ração pré-inicial comum a todas as aves. A partir do nono dia, as aves foram submetidas à dieta experimental com níveis de 3 , 6, 9 e 12\% de inclusão do farelo de algodão. O farelo de algodão apresentou 95,91\% de matéria seca, 9,8\% de gordura, $27 \%$ de proteína bruta, 4,6\% de cinza, $4.867 \mathrm{kcal}^{-1}$ de energia bruta, $1,32 \%$ de lisina e $0,35 \%$ de metionina. O valor de energia metabolizável aparente corrigida para nitrogenio determinado foi $1.188 \mathrm{kcal} \mathrm{kg}^{-1}$. Não se observou efeito no desempenho e no rendimento de carcaça dos frangos aos 42 dias de idade.

Palavras-chave: alimento alternativo, avicultura de corte, desempenho, digestibilidade, farelo de algodão, valor de energia.

\section{ABSTRACT}

The objective of the research was to determine the chemical and energetic composition of cottonseed meal produced by BUNGE Foods Company, trademark as high energy cottonseed meal (FAAE ${ }^{\circledR}$ ) and to evaluate its inclusion in the performance of broilers. The chemical, energetic and aminoacidic composition was determined using the total excretion gathering method, with two gathers a day. It was used ferric oxide to mark the beginning and the end of the gathering. The level of inclusion of the food testing in the reference diet was $20 \%$. The performance was evaluated with the inclusion of cottonseed meal in a period of 9 to 42 days. During the first nine days the poultries received pre-initial feed that were common to all birds. From the ninth day, the birds received an experimental diet with substitution levels of $3 \%$, $6 \%, 9 \%$ and $12 \%$ inclusion of cottonseed meal. The cottonseed meal presented $95.91 \%$ of dry matter, $9.8 \%$ of fat, $27 \%$ of crude protein, $4.6 \%$ of ash, $4.867 \mathrm{kcal} \mathrm{kg}^{-1}$ of crude energy, $1.32 \%$ of lysine and $0.35 \%$ of metionine. The determined value of apparent metabolizable energy corrected to nitrogen was $1.188 \mathrm{kcal} \mathrm{kg}^{-1}$. It was not observed effect in the performance and carcass return of the poultry at 42 days of age.

Key words: alternative feed, poultry, digestibility, performance, cottonseed meal, energy value.

\section{INTRODUÇÃO}

No Brasil, a formulação de rações para aves tem como alimentos tradicionalmente utilizados o milho e o farelo de soja. Estes dois alimentos chegam a representar $90 \%$ do total de ingredientes das rações, constituindo grande parte dos custos relativos à alimentação e, consequentemente, dos custos de produção. Tais alimentos estão sujeitos a intensas oscilações de preços. Assim, a busca por alimentos não convencionais é de fundamental importância (BARBOSA\& GATTÁS, 2004).

O farelo de algodão, produto obtido do caroço descorticado após a extração do óleo por

IPrograma de Pós-graduação em Zootecnia, Departamento de Zootecnia (DZ), Universidade Federal Rural de Pernambuco (UFRPE). Rua Dom Manuel de Medeiros, s/n, Dois Irmãos, 52171-900, Recife, Pernambuco, Brasil. E-mail: cleididacarvalho@hotmail.com. *Autor para correspondência 
solvente e moagem fina (BUTOLO, 2002), está entre os diversos alimentos que podem ser adicionados à ração de aves. Comercialmente são encontrados farelos com teores de proteína bruta (PB) que variam de 28 a 43\%, sendo o percentual de $\mathrm{PB}$ definido pela inclusão de casca no farelo. Porém, o elevado teor de fibra e a presença de gossipol são os fatores limitantes quanto à utilização desse ingrediente nas rações de monogástricos (BUTOLO, 2002).

SANTOS et al. (2005) encontraram valores de 3.131 e $3.095 \mathrm{kcal} \mathrm{kg}^{-1}$ para a energia metabolizável aparente corrigida pelo nitrogênio (EMAn), respectivamente, para farelos de algodão processados via extrusão e via extração com solvente, com teores de 32,96 e 35,11\% de PB, respectivamente.

Avaliando a substituição do farelo de soja pelo farelo do caroço de algodão, PIMENTEL (2006) concluiu que o farelo de algodão pode ser utilizado em até 19,41\%, em rações à base de aminoácidos digestíveis, sem afetar o desempenho e o rendimento de carcaça. OJEWALA et al. (2006) concluíram que o farelo de soja pode ser totalmente substituído pelo farelo de algodão, desde que seja observado o tratamento com ferro.

SANTOS (2006), avaliando a substituição da proteína do farelo de soja pela proteína do farelo de algodão (35,1\% PB), concluiu que até o nível de $40 \%$ de substituição não houve efeito sobre o ganho de peso e consumo de ração. Entretanto, ocorreu piora na conversão alimentar, o que exige uma análise econômica ao se utilizar tal substituição.

Assim, este trabalho teve como objetivos determinar a composição química e energética do farelo de algodão e avaliar a inclusão deste no desempenho de frangos de corte.

\section{MATERIAL E MÉTODOS}

Para avaliação nutricional do FAAE, foram determinados primeiramente a composição química e os valores de energia metabolizável, e posteriormente efetuou-se experimento para avaliar o efeito da inclusão do farelo no desempenho de frangos de corte.

Os experimentos de digestibilidade e desempenho foram realizados no setor de Avicultura do Departamento de Zootecnia (DZ) da Universidade Federal Rural de Pernambuco (UFRPE).

\section{Composição química}

A composição bromatólogica do $\mathrm{FAAE}^{\circledR}$ foi avaliada no Laboratório de Nutrição Animal (LNA/DZ/ UFRPE), onde foram determinados os teores de matéria seca (MS), proteína bruta (PB), extrato etéreo (EE), fibra bruta (FB), fibra em detergente neutro (FDN), fibra em detergente ácido (FDA) e matéria mineral (MM), de acordo com a metodologia descrita por SILVA \& QUEIROZ (2002). A análise de energia bruta (EB) foi realizada no Laboratório de Nutrição Animal do Departamento de Zootecnia da Universidade Federal da Paraíba.

Outra amostra foi enviada para o Laboratório Centro de Apoio Nutricional (CEAN) localizado na Universidade Federal de Santa Maria, Rio Grande do Sul (RS), para a determinação dos seguintes aminoácidos: asparina, glutamina, serina, glicina, histidina, arginina, treonina, alanina, prolina, tirosina, valina, metionina, cistina, isoleucina, leucina, fenilalanina e lisina.

\section{Ensaio metabólico}

Foi utilizado o método de coleta total de excretas, com pintos de corte da linhagem Ross, machos, com 14 dias de idade, alojados em baterias metálicas, providas de bebedouros tipo copo e comedouros tipo calha, para determinação dos coeficientes de metabolização aparente da matéria seca (CMAMS) e da energia bruta (CMAEB) e dos valores de energia metabolizável aparente (EMA) e energia metabolizável aparente corrigida para balanço de nitrogênio (EMAn) do FAAE ${ }^{\circledR}$.

Foi utilizado um delineamento experimental inteiramente ao acaso, com dois tratamentos e cinco repetições, sendo oito frangos por unidade experimental, por um período experimental de 10 dias, sendo cinco dias para adaptação às condições experimentais e cinco dias para a coleta de excretas, realizadas duas vezes ao dia. Acrescentou-se às rações o marcador fecal óxido férrico, na concentração de 1,0\%, possibilitando delimitar o início e o final do período de coleta de acordo com a metodologia adaptada de BRAGG et al. (1969).

As excretas coletadas foram acondicionadas em sacos plásticos devidamente identificados e armazenadas em freezer, sob uma temperatura de $-20^{\circ} \mathrm{C}$, até o final do experimento, quando então foram homogeneizadas por unidade experimental e encaminhadas para análises laboratoriais de MS, PB e EB.

Os tratamentos consistiram de uma ração de referência (T1) à base de milho e farelo de soja e uma ração de teste, constituída de $80 \%$ da ração referência e $20 \%$ do farelo de algodão. A ração de referência foi formulada com base na composição nutricional e energética obtida a partir de ROSTAGNO et al. (2005). 
A água e a ração foram fornecidas ad libitum.

A quantificação da ração ingerida e da produção de excretas possibilitou a determinação do coeficiente de digestibilidade aparente da matéria seca (CDAMS) e dos valores de EMA e EMAn dos farelo de algodão por meio de fórmulas propostas por MATTERSON et al. (1965). Considerando os valores de EB e de EMAn do ingrediente, foi calculado o coeficiente de metabolização aparente da energia bruta (CMAEB), seguindo a equação preconizada pelo ARC (1980), em que CMAEB=(EMAn/EB) $x 100$.

Ensaio de desempenho

Foram utilizados 350 pintos machos, da linhagem Coob, com nove dias de idade, peso inicial de 227,13g, distribuídos em um delineamento estatístico inteiramente casualizado, com cinco tratamentos, cinco repetições e 14 frangos por unidade experimental. Os tratamentos consistiram de cinco rações experimentais com níveis de 0, 3, 6, 9 e 12\% de FAAE ${ }^{\circledR}$.

As rações utilizadas foram isoproteicas, isocalóricas e isoaminoacídicas para metionina digestível, metionina + cistina digestíveis, lisina digestível e treonina digestível, conforme apresentado na tabela 1.

O desempenho zootécnico das aves foi aferido ao final de cada fase de criação e ao final de todo o ciclo de produção (9-42 dias) por meio do consumo de ração (CR), do ganho de peso (GP) e da conversão alimentar (CA).

Aos 42 dias de idade, três aves de cada repetição foram selecionadas de acordo com o peso médio de cada parcela, submetidas ao abate após o jejum de oito horas, por meio de corte na jugular, com sangria por três minutos. Em seguida, foram pesadas, escaldadas, depenadas, pesadas, evisceradas e pesadas novamente. Os cortes foram feitos 24 horas após o resfriamento das carcaças para, juntamente com o peso da gordura abdominal, que foi obtido por meio da pesagem da gordura extraída da região abdominal e aderida à cloaca, realizar o cálculo de rendimento dos cortes.

As variáveis avaliadas para o desempenho nas fases de nove a 21 dias e de 22 a 42 dias e durante todo o período experimental foram: consumo de ração (CR), ganho de peso (GP) e conversão alimentar (CA). Para a avaliação de rendimento de carcaça, foram utilizados os pesos de coxa + sobrecoxa, coxa, asa, peito, dorso, pescoço e gordura abdominal. Foram feitas as análises de variância e regressão ao nível de 5\% de probabilidade, utilizando-se o pacote estatístico SAEG(2007).

\section{RESULTADOS E DISCUSSÃO}

\section{Composição química}

Os resultados referentes à composição química do FAAE $^{\circledR}$ estão apresentados na tabela 2. Os valores encontrados neste trabalho, quando comparados com os valores encontrados na literatura, tanto nas tabelas nacionais, quanto em publicações internacionais, mostraram variações que podem ser justificadas pelos diferentes tipos de solos, climas, métodos de processamento e conteúdo de cascas na semente.

Os valores de PB, MM, FB e EB encontrados se mostraram menores do que os determinados pela EMBRAPA (1991), que foram de 38,74; 6,06; 11,98 e $4.193 \mathrm{kcal} \mathrm{kg}^{-1}$, respectivamente, enquanto que os valores de MS e EE de 88,10 e 1,8\% foram menores que os encontrados no presente trabalho.

Em comparação com os valores encontrados por ROSTAGNO et al. (2005), verificou-se que estes estão próximos, e os dados de PB (29,8\%) e MM (5,38\%) foram superiores, já os dados de FDN (41,70\%), FDA $(30,79 \%)$ e EE $(1,28)$ foram inferiores aos encontrados no presente trabalho. O valor de extrato etéreo $(6,57 \%)$ encontrado por OJEWALA et al. (2006) foi o que mais se aproximou do valor determinado neste experimento, e os demais valores foram inferiores, em relação à MS (89,38\%), EB (4.139 kcal kg-1) e FB (17,38\%).

O NRC (1994) traz informações para o farelo de algodão extraído com solvente, com níveis de 44,7\% de PB, $1,6 \%$ de extrato etéreo, $11,1 \%$ de FB e $91 \%$ de MS.

De acordo com SAKOMURA \& ROSTAGNO (2007), os aminoácidos essenciais estão entre os nutrientes que mais impactam o desempenho animal. Por isso, é de fundamental importância o conhecimento da composição em aminoácidos dos alimentos, bem como do seu aproveitamento pelos animais, o que tem possibilitado a substituição do milho e da soja por ingredientes alternativos, garantindo um aporte equivalente de aminoácidos digestíveis pela correção das deficiências com a suplementação de aminoácidos sintéticos.

No detalhamento da fração proteica do farelo de algodão, os valores encontrados se mostraram inferiores quando comparados com o farelo de soja.

Quando comparados com os valores para o farelo de algodão com 30\% de PB publicados por ROSTAGNO \& ALBINO (2005), os aminoácidos histidina (0,84\%), arginina (3,47\%), treonina $(0,97 \%)$, valina $(1,33 \%)$, metionina $(0,46 \%)$, isoleucina $(0,93 \%)$, lisina $(1,24 \%)$ se mostraram próximos aos encontrados no presente trabalho, com exceção da leucina $(1,76 \%)$ e fenilalanina $(1,61 \%)$. 
Tabela 1 - Composição percentual das rações experimentais utilizada na fase inicial (oito a 21 dias) e na fase final (22 a 42 dias) aminoácidos digestíveis (base MN).

\begin{tabular}{|c|c|c|c|c|c|c|c|c|c|c|}
\hline \multirow[t]{2}{*}{ Ingredientes } & \multicolumn{5}{|c|}{-------------Fase inicial (nove a 21 dias) ------------ } & \multicolumn{5}{|c|}{-----------------Fase final (22 a 42 dias) ----------------- } \\
\hline & 0 & 3 & 6 & 9 & 12 & 0 & 3 & 6 & 9 & 12 \\
\hline Milho & 62,06 & 59,67 & 57,27 & 54,88 & 52,49 & 64,12 & 61,66 & 59,20 & 56,74 & 54,28 \\
\hline Far. de Soja & 20,60 & 19,12 & 17,64 & 16,17 & 14,69 & 8,13 & 6,67 & 5,21 & 3,76 & 2,30 \\
\hline Soja Int. Ext. & 7,00 & 7,00 & 7,00 & 7,00 & 7,00 & 18,50 & 18,50 & 18,50 & 18,50 & 18,50 \\
\hline Glúten $60 \%$ & 6,00 & 6,00 & 6,00 & 6,00 & 6,00 & 5,50 & 5,50 & 5,50 & 5,50 & 5,50 \\
\hline Far. Algodão FAAE & 0,00 & 3,00 & 6,00 & 9,00 & 12,00 & 0,00 & 3,00 & 6,00 & 9,00 & 12,00 \\
\hline Óleo de Soja & 0,00 & 0,87 & 1,74 & 2,61 & 3,47 & 0,00 & 0,91 & 1,82 & 2,74 & 3,65 \\
\hline Fosf. Bicálcico & 1,85 & 1,82 & 1,80 & 1,78 & 1,76 & 1,64 & 1,61 & 1,59 & 1,57 & 1,54 \\
\hline Calcário & 0,93 & 0,93 & 0,94 & 0,95 & 0,96 & 0,87 & 0,88 & 0,88 & 0,89 & 0,90 \\
\hline Sal Comum & 0,50 & 0,50 & 0,50 & 0,50 & 0,50 & 0,47 & 0,47 & 0,47 & 0,47 & 0,47 \\
\hline L-Lisina & 0,46 & 0,47 & 0,49 & 0,50 & 0,51 & 0,34 & 0,35 & 0,35 & 0,36 & 0,37 \\
\hline Dl-Metionina & 0,22 & 0,22 & 0,22 & 0,22 & 0,22 & 0,15 & 0,15 & 0,15 & 0,16 & 0,16 \\
\hline L-Treonina & 0,11 & 0,11 & 0,12 & 0,12 & 0,12 & 0,03 & 0,04 & 0,05 & 0,06 & 0,07 \\
\hline Suplemento Vit. ${ }^{1}$ & 0,10 & 0,10 & 0,10 & 0,10 & 0,10 & 0,10 & 0,10 & 0,10 & 0,10 & 0,10 \\
\hline Suplemento Min. $^{2}$ & 0,05 & 0,05 & 0,05 & 0,05 & 0,05 & 0,05 & 0,05 & 0,05 & 0,05 & 0,05 \\
\hline Albac $^{3}$ & 0,04 & 0,04 & 0,04 & 0,04 & 0,04 & 0,04 & 0,04 & 0,04 & 0,04 & 0,04 \\
\hline Cygro $^{4}$ & 0,04 & 0,04 & 0,04 & 0,04 & 0,04 & 0,04 & 0,04 & 0,04 & 0,04 & 0,04 \\
\hline Cloreto de Colina & 0,04 & 0,04 & 0,04 & 0,04 & 0,04 & 0,03 & 0,03 & 0,03 & 0,03 & 0,03 \\
\hline Total & 100,00 & 100,00 & 100,00 & 100,00 & 100,00 & 100,00 & 100,00 & 100,00 & 100,00 & 100,00 \\
\hline EM, $\left(\mathrm{kcal} \mathrm{kg}^{-1}\right)$ & 3.056 & 3.054 & 3.053 & $\begin{array}{l}\text { mposiçãc } \\
3.051\end{array}$ & $\begin{array}{c}\text { utricion } \\
3.049\end{array}$ & 3.210 & 3.210 & 3.210 & 3.210 & 3.210 \\
\hline $\mathrm{PB} \%$ & 21,20 & 21,20 & 21,20 & 21,20 & 21,20 & 19,52 & 19,51 & 19,50 & 19,49 & 19,48 \\
\hline Cálcio \% & 0,89 & 0,89 & 0,89 & 0,89 & 0,89 & 0,82 & 0,82 & 0,82 & 0,82 & 0,82 \\
\hline Fósf. Dig.\% & 0,45 & 0,45 & 0,45 & 0,45 & 0,45 & 0,41 & 0,41 & 0,41 & 0,41 & 0,41 \\
\hline Met dig., \% & 0,55 & 0,54 & 0,54 & 0,54 & 0,54 & 0,45 & 0,45 & 0,45 & 0,45 & 0,45 \\
\hline Met+Cys. dig.,\% & 0,85 & 0,85 & 0,85 & 0,85 & 0,85 & 0,74 & 0,74 & 0,74 & 0,74 & 0,74 \\
\hline Lys dig., \% & 1,21 & 1,21 & 1,21 & 1,20 & 1,20 & 1,03 & 1,03 & 1,03 & 1,03 & 1,03 \\
\hline Thr. dig., \% & 0,81 & 0,80 & 0,79 & 0,79 & 0,78 & 0,67 & 0,67 & 0,67 & 0,67 & 0,67 \\
\hline Trp Dig., \% & 0,20 & 0,20 & 0,20 & 0,21 & 0,21 & 0,18 & 0,18 & 0,18 & 0,18 & 0,18 \\
\hline Sódio, \% & 0,22 & 0,22 & 0,22 & 0,22 & 0,22 & 0,20 & 0,20 & 0,20 & 0,20 & 0,20 \\
\hline Potássio, \% & 0,75 & 0,73 & 0,71 & 0,68 & 0,66 & 0,67 & 0,65 & 0,63 & 0,61 & 0,59 \\
\hline Gordura, \% & 3,97 & 5,02 & 6,07 & 7,12 & 8,17 & 5,85 & 6,95 & 8,04 & 9,13 & 10,22 \\
\hline Fibra,\% & 2,69 & 3,26 & 3,83 & 4,40 & 4,96 & 2,76 & 3,33 & 3,90 & 4,47 & 5,04 \\
\hline
\end{tabular}

${ }^{1}$ Quantidade/kg de ração (amount/kg of diet): vit. A - 11.000U.I.; vit. D3 - 2.000U.I.; vit. E - 16U.I.; ácido fólico (folic acid) - 0,4mg; Pantotenato de Cálcio (pantothenic of calcium) - 10,0mg; biotina (biotin) - 0,06mg; Niacina (Niacin) - 35mg; Piridoxina (piridoxin) - 2,0mg; Riboflavina (riboflavin) - 4,5mg; Tiamina (tiamin) - 1,2mg; vit. B12 - 16,0mg; vit. K3 - 1,5mg; selênio (selenium) - 0,25mg; Antioxidante (Antioxidant) - 30mg.

${ }^{2}$ Quantidade/kg de ração (amount/kg of diet): Mn - 60,0mg; Fe - 30,0mg; Zn - 60,0mg; Cu - 9,0mg; I - 1,0mg.

${ }_{3}^{3}$ Cada $100 \mathrm{~g}$ do produto contém: Maduramicina (1,0g), Álcool benzílico (4,0g), Óleo de milho refinado (3,3g), Gérmen de milho (100,0g).

${ }^{3}$ Bacitracina de Zinco a $15 \%$

O NRC (1994) apresenta valores de PB $(37,4 \%)$, porém traz baixos valores de arginina $(0,466)$, alanina $(0,142)$, metionina $(0,153)$, lisina $(0,158)$, quando comparados com os resultados do presente trabalho.

A EMBRAPA (1991) traz valores próximos para histidina (1,01\%), arginina (3,99\%), cistina $(0,73 \%)$, superiores para fenilalanina $(1,87 \%)$, glutamina $(5,74 \%)$ e inferiores para asparina $(3,67 \%)$, serina $(1,82 \%)$, glicina
$(1,59 \%)$, treonina $(1,34 \%)$, alanina $(1,85 \%)$, prolina $(1,57 \%)$, tirosina $(1,11 \%)$, valina $(1,72 \%)$, metionina $(0,61 \%)$, isoleucina $(1,26 \%)$, leucina $(2,32 \%)$ e lisina $(1,5 \%)$.

Ensaio de Metabolismo

Os coeficientes de metabolização aparente da matéria seca (CMAMS), os coeficiente de 
Tabela 2 - Composição química do farelo de algodão FAAE ${ }^{\circledR}$ utilizado no experimento (base $\mathrm{MN}$ ).

\begin{tabular}{|c|c|}
\hline Nutrientes $^{1}$ & Farelo de algodão ${ }^{4}$ \\
\hline MS, \% & 95,91 \\
\hline $\mathrm{PB}, \%$ & 27,00 \\
\hline EE, \% & 9,80 \\
\hline FDN, \% & 48,00 \\
\hline FDA, \% & 34,00 \\
\hline MM, \% & 4,60 \\
\hline $\mathrm{FB}, \%$ & 29.04 \\
\hline \multicolumn{2}{|l|}{ Aminoácidos ${ }^{2}$} \\
\hline Asparina \% & 2,67 \\
\hline Glutamina \% & 6,05 \\
\hline Serina \% & 1,32 \\
\hline Glicina \% & 1,19 \\
\hline Histidina \% & 1,07 \\
\hline Arginina \% & 3,91 \\
\hline Treonina \% & 0,95 \\
\hline Alanina \% & 1,17 \\
\hline Prolina \% & 1,22 \\
\hline Tirosina \% & 0,89 \\
\hline Valina \% & 1,47 \\
\hline Metionina \% & 0,35 \\
\hline Cistina \% & 0,69 \\
\hline Isoleucina \% & 1,07 \\
\hline Leucina \% & 2,09 \\
\hline Fenilalanina \% & 2,34 \\
\hline Lisina \% & 1,32 \\
\hline $\mathrm{EB}^{3}, \mathrm{kcal} \mathrm{kg}^{-1}$ & 4.867 \\
\hline
\end{tabular}

${ }^{1}$ Análises realizadas no Laboratório de Nutrição Animal do Departamento de Zootecnia da Universidade Federal Rural de Pernambuco.

${ }^{2}$ Análise realizada no Laboratório do Centro de Apoio Nutricional (CEAN) da Universidade Federal de Santa Maria - RS.

${ }^{3}$ Análise realizada no Laboratório de Nutrição Animal do Departamento de Zootecnia da Universidade federal da Paraíba

${ }^{4}$ FAAE - BUNGE.

metabolização aparente da energia bruta (CMAEB) e os valores de energia metabolizável aparente (EMA) e energia metabolizável corrigida para o balanço de nitrogênio (EMAn) são apresentados na tabela 3. O valor de EMA obtido no presente estudo (1.416 kcal $\mathrm{kg}^{-1}$ ) se mostrou menor que os determinados pela EMBRAPA (1991), que foi de $2.174 \mathrm{kcal} \mathrm{kg}^{-1}$, e por ROSTAGNO et al. (2005) de 1.666 $\mathrm{kcal} \mathrm{kg}^{-1}$, assim como o NRC (1994), que traz o farelo de algodão extraído com solvente com $1.887 \mathrm{kcal} \mathrm{kg}^{-1}$ de energia metabolizável corrigida para o balanço de nitrogênio.

Segundo TORRES (1979), quando ocorre a inclusão total da casca ao farelo, o teor de PB é de 28\%, assim como o teor de FB é aumentado sensivelmente, reduzindo a capacidade de metabolização pelas aves. Sendo assim, os altos valores de EB não representam necessariamente altos valores para a CMAEB, EMA e EMAn.

Os baixos valores encontrados para o coeficiente de metabolização da energia bruta podem também ser explicados pela interação existente entre a baixa capacidade de digestão e absorção de frangos de corte jovens, com idade média de 21 dias (ALBINO et al., 1982) e os altos teores de fibra bruta presentes no farelo de algodão. LIMA et al. (2007) observaram que aves com diferentes idades apresentaram valores crescentes de metabolização do farelo de glúten 21\%, com teores de fibra bruta próximos a 10\%.

Ensaio de desempenho

Os resultados de desempenho e as médias das características de carcaça de frangos de corte alimentados com diferentes níveis da inclusão do farelo de algodão na alimentação de frangos de corte aos 42 dias de idade estão presentes na tabela 4 .

Pelos resultados obtidos, pode-se observar que não houve diferenças significativas $(\mathrm{P}>0,05)$ entre os tratamentos para os dados de desempenho, tanto na fase de recria ( 9 a 12 dias), como na fase de terminação (22 a 42 dias).

GAMBOA et al. (2001), avaliando dietas para frangos de corte com base na digestibilidade dos aminoácidos, incluíram 0, 7, 14, 21, 28\% de farelo de algodão nas dietas inicial e final, as quais foram formuladas para ter níveis similares de lisina e metionina digestíveis, e observaram que o farelo de algodão pode ser usado na alimentação de frangos de corte em até $21 \%$ do total da dieta, desde que seja considerada a digestibilidade dos aminoácidos.

Da mesma forma, HENRY et al. (2001) avaliaram o desempenho de frangos de corte entre sete e 21 dias, concluindo que a inclusão de $20 \%$ de farelo de algodão (44\% PB), com a incorporação de $2 \%$ de lisina, não afetou o desempenho das aves.

Pode-se observar um maior coeficiente de variação apenas para gordura abdominal. Este fato pode ser explicado em função do aumento da quantidade de óleo de soja que foi adicionado à ração

Tabela 3 - Médias dos coeficientes de metabolização aparente da matéria seca (CMAMS) e da energia bruta (CMAEB), valores de energia metabolizável aparente (EMA) e energia metabolizável aparente corrigida para o balanço de nitrogênio (EMAn) do FAAE ${ }^{\circledR}$.

\begin{tabular}{lcc}
\hline \multicolumn{1}{c}{ Variáveis } & Matéria seca & Matéria natural \\
\hline CMAMS\% & $27,47 \pm 5,04$ & $26,35 \pm 4,84$ \\
EMA, kcal kg-1 & $1.416 \pm 0,197$ & $1.358 \pm 0,189$ \\
EMAn, kcal kg-1 & $1.239 \pm 0,186$ & $1.188 \pm 0,178$ \\
CMAEB\% & $25,46 \pm 3,81$ & $24,42 \pm 3,66$ \\
\hline
\end{tabular}


Tabela 4 - Resultados de desempenho e médias das características de carcaça de frangos alimentados com os diferentes níveis de FAAE ${ }^{\circledR}$ em substituição ao milho e farelo de soja.

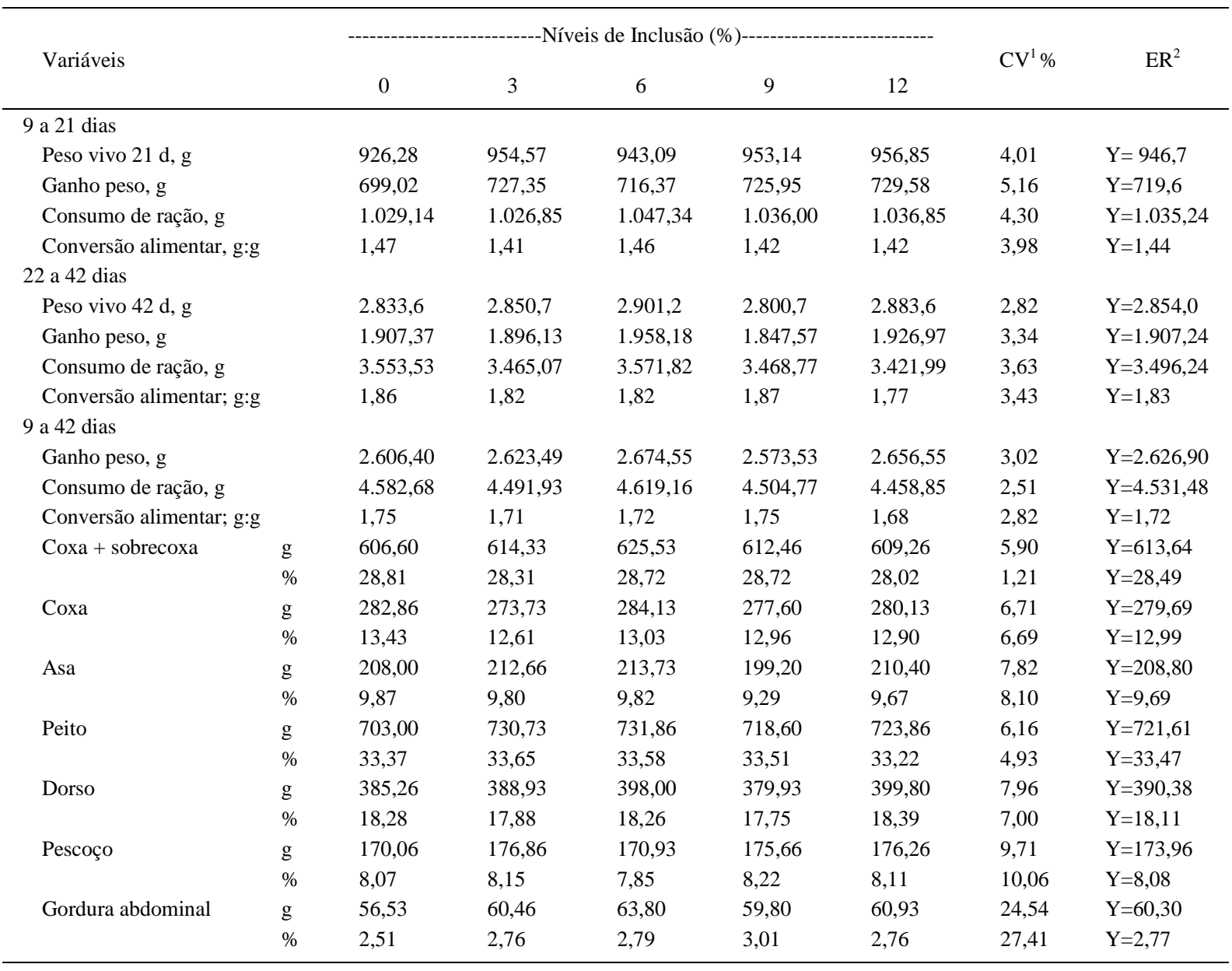

${ }^{1}$ CV: Coeficiente de Variação.

${ }^{2}$ ER: Equação de Regressão.

Probabilidade: $(\mathrm{P}>0,05)$.

proporcionalmente ao aumento dos níveis de inclusão do farelo de algodão, uma vez que o consumo de ração em frangos é regulado pela energia da ração, e o óleo de soja é o melhor ingrediente para fornecer energia suplementar numa ração. As variáveis não apresentaram diferenças significativas nas avaliações quando comparadas em gramas ou percentuais.

OJEWALA et al. (2006) avaliaram o efeito da substituição do farelo de soja pelo farelo de algodão, concluindo que não houve alteração no desempenho de frangos de corte, com melhoria significativa do resultado econômico.

STERLING et al. (2002), trabalhando com aves alimentadas com níveis crescentes (17, 20 e 23\%) de fontes de proteína (farelo de soja e farelo de algodão) baseados na proteína dietética, concluíram que as fontes e os níveis de proteína promoveram efeito no peso de carcaça fria, filé e gordura abdominal, mas não sobre dorso e peito. No entanto, quando os rendimentos foram analisados com relação ao percentual de peso vivo, ocorreu aumento significativo no rendimento do peito para os animais alimentados com o farelo de algodão, resultado que não foi observado neste trabalho.

Da mesma forma, SANTOS (2006) encontrou aumento do rendimento de peito, coxa+sobrecoxa, asa e dorso+pescoço à medida que se aumentaram os níveis de substituição da proteína do farelo de soja pelo farelo de algodão (35,1\% PB) até $40 \%$ em dietas para frangos de corte.

Por outro lado, PIMENTEL (2006), avaliando o efeito da substituição da proteína do farelo de soja por farelo do caroço de algodão extrusado até o nível de $40 \%$, não encontrou diferenças significativas nos rendimentos de carcaça e cortes comerciais de frango de corte. 


\section{CONCLUSÕES}

O FAAE ${ }^{\circledR}$ apresentou 95,91\% de matéria seca, $9,8 \%$ de gordura, $27 \%$ de proteína bruta, 4,6\% de cinza, 4.867 $\mathrm{kcal} \mathrm{kg}^{-1}$ de energia bruta, 1,32\% de lisina e 0,35\% de metionina. O valor de energia metabolizável aparente corrigida para nitrogênio determinado para frangos de corte foi de $1.188 \mathrm{kcal} \mathrm{kg}^{-1}$. O farelo de algodão de qualidade semelhante ao do presente experimento pode ser utilizado na alimentação de frangos de corte até o nível de 12\% de inclusão, sem interferir nos resultados de desempenho e rendimento de carcaça.

\section{AGRADECIMENTOS}

À empresa BUNGE Alimentos S/A, pelo apoio ao experimento, na figura dos senhores Sílvio Souza e Sr. Júnio Barroso, e ao CNPq, pela concessão de bolsa de estudos.

\section{REFERÊNCIAS}

ALBINO, L.F.T. et al. Determinação dos valores de energia metabolizável e matéria seca aparentemente metabolizável de alguns alimentos. Revista Brasileira de Zootecnia, v.11, n.2, p.207-221, 1982.

ARC - AGRiCUlTURAL RESEARCH COUNCIL. The nutrient requirements of farm livestock. London, 1980. 351p.

BARBOSA, F.F.; GATTÁS, G. Farelo de algodão na alimentação de suínos e aves. Revista Eletrônica Nutritime. Artigo número 15 - publicado em 11 de novembro de 2004. Disponível em: <http:/www.nutritime.com.br/arquivos_intenos/artigos/ 015V1N3P147_156_NOV2004.pdf >. Acesso em: 14 out. 2006.

BUTOLO, J.E. Qualidade de ingredientes na alimentação animal. Campinas: Pfizer Saúde Animal. 2002. 430p.

BRAGG,D.B. et al. Methods for determining amino acid availability of feeds. Poultry Science, v.48, p.2135-2137, 1969.

EMBRAPA - EMPRESA BRASILEIRA DE PESQUISA AGROPECUÁRIA. Centro Nacional de Pesquisa de Suínos e Aves. Tabela de composição química e valores energéticos de alimentos para suínos e aves. 3.ed. Concórdia, 1991. (Embrapa - CNPSA. Documentos,19).

GAMBOA. D.A. et al. Tissue distribution of gossypol enantiomers in broilers fed various cottonseed meals. Poultry Science, v.80, n.7, p.920-925, 2001.

HENRY, M.H. et al. The performace or broiler chicks fed diets containing extruded cottonseed meal supplemented with lysine. Poultry Science, v.80, p.762-768, 2001.
LIMA, S.B.P. et al. Avaliação nutricional e energética do farelo de glúten $21 \%$ para frangos de corte caipira. In: CONGRESSO LATINO AMERICANO DE AVICULTURA, 20., 2007, Porto Alegre, RS. Anais... Porto Alegre, 2007. CD-ROM.

MATTERSON, L.D. et al. The metabolizable energy of feed ingredients for chickens. Research Report, v.7, n.1, p.3-11, 1965.

NRC - NATIONAL RESEARCH COUNCIL. Nutrient requirement of poultry. 9.ed. Washington, DC, 1994. 176p.

OJEWOLA, G.S. et al. Cottonseed meal as substitute for soybean meal in broiler ration. International Journal of Poultry Science, v.5. n.4 p.360-364, 2006.

PIMENTEL, A.C.S. Substituição do milho e do farelo de soja por sorgo e farelo de caroço de algodão extrusado em rações para frangos de corte. 2006. 68f. Dissertação (Mestrado em Zootecnia) - Universidade Federal Rural de Pernambuco, Recife, PE.

ROSTAGNO, H.S.; ALBINO, L.F.T. Simpósio Internacional sobre Exigências Nutricionais de Aves e Suínos. Anais... Viçosa: UFV, 2005. CD-ROM

ROSTAGNO, H.S. et al. Tabelas brasileiras para aves e suínos: composição de alimentos e exigências nutricionais. 2.ed. Viçosa, MG: Universidade Federal de Viçosa, 2005. 186p.

SAEG - Sistema para Análise Estatísticas. Viçosa: Universidade Federal de Viçosa, 2007. CD-ROM.

SAKOMURA, N.K.; ROSTAGNO, H.S. Métodos de pesquisa em nutrição de monogástricos. Jaboticabal: Funep, 2007. 283p.: il.

SANTOS, M.J.B. et al. Efeito do processamento do farelo de algodão sobre a composição nutricional e valor de energia metabolizável para frangos de corte. In: ZOOTEC, 2005, Campo Grande, MS. Anais... Campo Grande: ZOOTEC, 2005. CD ROM

SANTOS, A.P.S.F. Efeito da substituição da proteína do farelo de soja pela proteína do farelo de algodão sobre o desempenho e avaliação de carcaças em frangos de corte. 2006. 55f. Dissertação (Mestrado em Zootecnia) - Universidade Federal Rural de Pernambuco, Recife, PE.

SILVA, D.J.; QUEIROZ, A.C. de. Análise de alimentos: métodos químicos e biológicos. 3.ed. Viçosa: Universidade Federal de Viçosa, 2002. 235p.

STERLING, K.G. et al. Responses of broiler chickens to cottonseed- and soybean meal- based diet at several protein levels. Poultry Science, v.81, n.2, p.217-226, 2002.

TORRES, A.P. Alimentos e nutrição das aves domésticas. 2.ed. São Paulo: Editora Nobel, 1979. 324p. 